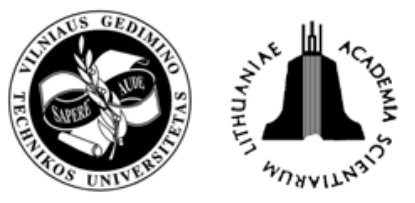

\title{
PERSONNEL SUPPLY AND DEMAND FOR CIVIL AVIATORS IN TAIWAN
}

\author{
Chin-Tsai Lin ${ }^{1}$, Pin-Ju Juan ${ }^{2}$ \\ ${ }^{1}$ School of Management, Ming Chuan University, Taipei, Taiwan. E-mail: ctlin@mail.ypu.edu.tw \\ ${ }^{2}$ School of Management, Ming Chuan University, 250 Chung Shan N. Rd. Sec. 5, Taipei 11103, Taiwan \\ E-mail: s3975021@ss24.mcu.edu.tw
}

Received 4 February 2007; accepted 10 September 2007

\begin{abstract}
This work was based on data from 2000-2005 provided by the Civil Aeronautics Administration Ministry of Transportation and Communications, and applied the GM $(1,1)$ model of Grey theory to forecast annual demand and supply for civil aviators in Taiwan. This work adopted a five-year moving average to calculate the transition probability for civil aviators in Taiwan from 2006-2010 considering various levels of seniority. The study results provide a valuable reference for the relevant authorities in identifying the manpower policies of Taiwanese airlines.
\end{abstract}

Keywords: Aviators, pilot, co-pilot, labor employment, supply and demand analysis.

\section{Introduction}

Civil aviation plays an important role in the development of the world economy [1]. Forecasts by the International Air Transport Association (IATA) for passengers and freight stated that passenger flows in the Asia Pacific region will experience some of the fastest growth in the world in the medium-term [2]. In 2003, Taiwanese civilian airplanes were permitted to fly to the Chinese mainland for the first time since 1949. Based on this relaxation of regulations, services have been established to transport Taiwanese business people back home for the holidays [3]. Direct air links between China and Taiwan appear inevitable given that the two states perform mutually dependent functions in the global manufacturing supply chain [4]. Taiwan ranks among the top 20 nations internationally in terms of air travel, with over 2 million passengers traveling by air annually, according to the ranking of AAGR 2005-2009 [2]. Air travel in Taiwan is growing by an annual average of $6.5 \%$. Input of civil aviation manpower has contributed significantly to Taiwanese civil aviation industry development. Specifically, the quality of civil aviators and the structure of their hierarchy influence airline operations. Civil aviators in Taiwan belong to two rankings, captain and co-pilot. Sources of pilots in Taiwan include expatriate pilots, ex-military pilots, self-sponsored pilots, and sponsored pilot training schemes.

During mid-2003, a total of 41 airlines, including code-share airlines, provided services to Taiwanese destinations. Of these airlines, 35 foreign carriers and six domestic carriers (China Airlines, EVA, Mandarin, Trans-Asia, UNI, and Far-Eastern) operated scheduled international services to and from Taiwan. Furthermore, six domestic carriers, including two helicopter operators, also offered domestic passenger services [5]. Notably, the largest carrier in Taiwan, China Airlines (CAL) plans to hire 100 trainee pilots to meet the needs associated with the addition of new routes and additional aircraft purchases. CAL will visit local university campuses to seek potential pilots, who will typically require two years training to reach the rank of co-pilot [6].

The study of native pilot selection for civilian airliners is that sponsored pilots training (63.64\%), CPL pilots $(23.64 \%)$ and ex-military pilots $(12.73 \%)$. The development of the Taiwanese air industry has also created a need for training schemes [7]. The pilots of most global air carriers usually fly only one type of aircraft. This arrangement is primarily motivated by safety concerns (the idea is to adapt the pilot as much as possible to a certain type of aircraft). Therefore, when a fleet contains different aircraft types, separate monthly schedules are made for the pilots of different aircraft types [8].

Most studies on airline crew scheduling problems have only considered pilot or attendant scheduling problems [9]. Few previous studies have considered the pilot manpower supply and demand numbers forecasting problem. Forecasting methods adopted in this work include linearity regression analysis, time series analysis and grey system theory [10-13]. However, linearity regression analysis requires massive samples and sample distribution. Furthermore, the time series analysis requires the same tendency and stable historical data. Owing to a lack of data from the Civil Aeronautics Administration Ministry of Transportation and Communications in Taiwan, this work was unable to employ other general statistical numerical methods. Consequently, this study thus applied grey system theory to create a forecast- 
ing model owing to its minimal data requirements. The GM model bases model establishment on knowledge of the system data for four pieces of data. Additionally, knowledge of future system development tendencies is required before making the prediction to rely on seeking the ruler's data itself for the forecasting method adopted [14]. Nevertheless, the GM $(1,1)$ model contains little data that can be used to what is useful in forecasting. This work thus develops a forecasting model for GM $(1,1)$, and applies it to forecast supply and demand for civil aviators in Taiwan.

Social science researchers use models and data for forecasting [15]. Deng [16] designed the grey-forecasting model (GM), which forms the core of grey system theory and helps enhance prediction accuracy. Yi [17] applied the Grey model to forecast human ability. Meanwhile, in marketing management, Lin and Hsu [18] applied grey theory to forecast the advertising revenue of the five largest Internet-based media companies in Taiwan. Additionally, in the human resource literature, Lin et al. [19] applied the GM $(1,1)$ model of Grey theory to forecast annual demand for deck officers, and used cross analysis to manpower supply and demand for ocean deck officers in Taiwan.

All of these previous studies have demonstrated the value of using the Grey model to enhance information quality. This work, based on the number of airlines in Taiwan from 2000-2005, established a Grey model for forecasting demand at each level in the Taiwanese civil aviation hierarchy during 2006-2010. The study provided references for government departments in devising labor policies for civil aviators in Taiwan.

\section{Grey model}

This section describes Grey models. Grey Model (GM) comprises the basis of the Grey System as well as the core of Grey System Theory. Grey System Theory treats all variables within a given range as Grey capacity, and all the variables used in the procedure are time related. Grey capacity is not achieved by formulating statistical regulations. The nature of internal regularity in managing disorganized primitive data. GM is established by transferring the arranged sequence into a differential equation. The following illustration develops the method used to build the work model by establishing a sequence of one order linear moving GM $(1,1)$ [16].

Assume that $x^{(0)}$ represents the primitive series

$$
x^{(0)}=\left(x^{(0)}(1), x^{(0)}(2), \cdots, x^{(0)}(n)\right) .
$$

During model establishment, the grey system must apply the primitive series to perform the Accumulated Generating Operation (AGO) to provide the middle message for model construction and variation reduction. Moreover, $x^{(1)}$ is defined as the one order AGO series of $x^{(0)}$ as follows:

$$
\begin{aligned}
& x^{(1)}=\left(x^{(1)}(1), x^{(1)}(2), \cdots, x^{(1)}(n)\right)= \\
& {\left[\sum_{k=1}^{1} x^{(0)}(k), \sum_{k=1}^{2} x^{(0)}(k), \cdots, \sum_{k=1}^{n} x^{(0)}(k)\right] .}
\end{aligned}
$$

From series $x^{(0)}$ and $x^{(1)}$, a grey difference equation is formed as follows:

$$
x^{(0)}(k)+a z^{(1)}(k)=b, \forall k=2,3, \cdots, n,
$$

where

$$
z^{(1)}=0.5 x^{(1)}(k)+0.5 x^{(1)}(k-1) .
$$

According to Eqn. (3), Eqn. (4) and the ordinary least square method, coefficient $\hat{a}$ becomes

$$
\hat{a}=\left[\begin{array}{l}
a \\
b
\end{array}\right]=\left(B^{T} B\right)^{-1} B^{T} y_{n},
$$

where

$$
B=\left[\begin{array}{cc}
-z_{1}^{(1)}(2) & 1 \\
-z_{1}^{(1)}(3) & 1 \\
\cdot & \cdot \\
\cdot & \cdot \\
\cdot & \cdot \\
-z_{1}^{(1)}(n) & 1
\end{array}\right]
$$

and

$$
y_{n}=\left[x^{(0)}(2), x^{(0)}(3), \cdots, x^{(0)}(n)\right]^{T} .
$$

Next, to solve $x^{(1)}$ in Eqn. (4), the associated is used, as follows:

$$
\frac{d x^{(1)}}{d t}+a x^{(1)}=b
$$

The approximate relationship can be obtained as follows by substituting the obtained $\hat{a}$ into Eqn. (6) and solving the following equation:

$$
\hat{x}^{(1)}(k+1)=\left[x^{(0)}(1)-\frac{b}{a}\right] e^{-a k}+\frac{b}{a},
$$

where $x^{(1)}(1)=x^{(0)}(1)$, the obtained data (6) are employed to perform the Inverse-Accumulated Generating Operation (IAGO). The series must then be reduced as shown in Eqn. (8).

$$
\hat{x}^{(0)}(k)=\left[x^{(0)}(1)-\frac{b}{a}\right] e^{-a(k-1)}\left(1-e^{a}\right) .
$$

Given $k=1,2, \ldots, n$, the sequence of reduction is obtained as follows:

$$
\hat{x}^{(0)}=\left(\hat{x}^{(0)}(1), \hat{x}^{(0)}(2), \cdots, \hat{x}^{(0)}(n)\right) .
$$

To determine the efficiency of the proposed forecasting model, this work employs the residual error test method to compare the forecasted and actual values. The following formula was used 


$$
e(k)=\frac{\left|x^{(0)}(k)-\hat{x}^{(0)}(k)\right|}{x^{(0)}(k)} \times 100 \%, k=2,3, \ldots, n .
$$

The accuracy was $1-e(k)$, and the model was considered useful provided the average accuracy exceeds $90 \%$.

\section{Empirical applications}

This work adopted a six-year moving average to calculate the transition probability of civil aviators in Taiwan from 2000-2005 at different hierarchical levels. This work applied the GM $(1,1)$ model of Grey theory to forecast annual supply and demand for civil aviators.

\subsection{Forecast supply of civil aviators}

\subsubsection{Analysis of air civil aviator supply}

This work compiled numbers of civil aviators, as well as the ranks of licensed civil aviators. The number of civil aviators in Taiwan during 2000-2005 was also obtained, as listed in Table 1 [20].

\subsubsection{Grey forecast of supply of air civil aviators}

This forecast is determined by the number of airline transport pilot licenses in the Taiwan area. Consequently, the forecast annual number of Taiwanese airline pilots provides a proxy for the annual supply of civil aviators. Based on the GM $(1,1)$ Grey model and data in Table 1, this work calculates the number of captains in Taiwan for each year from 2000-2005. An explanation follows: Eqn. (1) and Table 1 provide a primitive sequence $x^{(0)}$ that is $x^{(0)}=(621,658,677,695,712,724)$.

Eqn. (2) yields a single order AGO sequence of $x^{(1)}$

$$
x^{(1)}=(621,1279,1956,2651,3363,4087) .
$$

Additionally, matrix B and constant vector $y_{n}$ are obtained as follows

$$
B=\left[\begin{array}{ll}
-950 & 1 \\
-1617.5 & 1 \\
-2303.5 & 1 \\
-3007 & 1 \\
-3725 & 1
\end{array}\right]
$$

and

$$
y_{n}=\left[\begin{array}{l}
658 \\
677 \\
695 \\
712 \\
724
\end{array}\right] .
$$

Eqn. (4) gives $\hat{a}$ as

$$
\hat{a}=\left[\begin{array}{l}
a \\
b
\end{array}\right]=\left[\begin{array}{c}
-0.02403 \\
637.4264
\end{array}\right] .
$$

The forecasting model is obtained by substituting $a$ and $b$ into Eqn. (7)

$$
\hat{x}^{(0)}(k)=27142.74 e^{0.02403(k-1)}\left(1-e^{-0.02403}\right) .
$$

The forecast values of the total numbers of civil aviators from 2001-2004 (621, 660, 676, 693, 710 and 727, respectively), are obtained by substituting $k=2,3, \ldots, 6$ into Eqn. (10), and the reduction sequence is $x^{(0)}=(621$, $660,676,693,710,727)$.

Table 2 shows that the forecast value, actual value, and residual error can be derived by substituting $x^{(0)}(k)$ and $\hat{x}^{(0)}(k), k=2,3, \ldots, 6$ into Eqn. (9). Moreover, the table also shows that the average residual error is $0.2994818 \%$, while the average accuracy is $99.70052 \%$; furthermore, the maximal residual error is $0.40 \%$ and the maximum accuracy is $99.90 \%$. The above statistics confirm the accuracy of the forecasting model.

Given $k=6,7,8,9,10$, then from Eqn. (10), the annual forecast numbers of civil aviators for 2006-2010 are $745,763,781,800$, and 820 , respectively. Table 3 lists the outcome.

Table 3 lists that, based on the supply of every level of civil aviators during 2010, little annual variation existed in captain supply. Notably, co-pilots supply is expected to enter an annual decline from 2006 to 2010 . The annual rates of decline for co-pilots are $0.92 \%, 0.92 \%$, $0.93 \%$ and $0.81 \%$, respectively. The above figures clearly indicate a decline in the supply of co-pilots. However, whether this tendency will produce a serious long-term imbalance in labor supply and demand for captains and co-pilots remains uncertain. Further discussion is re-

Table 1. Statistics for airline transport pilot license in Taiwan (unit: per person)

\begin{tabular}{|l|c|c|c|c|c|c|}
\hline \multicolumn{1}{|c|}{ Year } & 2000 & 2001 & 2002 & 2003 & 2004 & 2005 \\
\hline $\begin{array}{l}\text { Captain of } \\
\text { Taiwanese }\end{array}$ & 621 & 658 & 677 & 695 & 712 & 724 \\
\hline $\begin{array}{l}\text { Co-pilot of } \\
\text { Taiwanese }\end{array}$ & 824 & 825 & 781 & 760 & 769 & 796 \\
\hline Total & 1,445 & 1,483 & 1,458 & 1,455 & 1,481 & 1,520 \\
\hline The source of information: [20]. \\
\hline
\end{tabular}

Table 2. Forecast value, real value and residual error of captain supply

\begin{tabular}{|l|c|c|c|c|c|}
\hline \multicolumn{1}{|c|}{ Year } & 2001 & 2002 & 2003 & 2004 & 2005 \\
\hline$k$ value & 2 & 3 & 4 & 5 & 6 \\
\hline $\begin{array}{l}\text { Actual quantity of } \\
\text { captain } x^{(0)}(k)\end{array}$ & 658 & 677 & 695 & 712 & 724 \\
\hline $\begin{array}{l}\text { Forecast quantity of } \\
\text { captain } \hat{x}^{(0)}(k)\end{array}$ & 660 & 676 & 693 & 710 & 727 \\
\hline $\begin{array}{l}\text { Residual error }(\%) \\
e(k)\end{array}$ & 0.34 & 0.10 & 0.31 & 0.33 & 0.40 \\
\hline
\end{tabular}

Table 3. Forecast supply of civil aviators for 2006-2010 (unit: per person)

\begin{tabular}{|l|c|c|c|c|c|}
\hline \multicolumn{1}{|c|}{ Year } & 2006 & 2007 & 2008 & 2009 & 2010 \\
\hline Captain & 745 & 763 & 781 & 800 & 820 \\
\hline Co-pilot & 765 & 758 & 751 & 744 & 738 \\
\hline Total & 1,510 & 1,521 & 1,532 & 1,544 & 1,558 \\
\hline
\end{tabular}


quired regarding demand at all levels of the hierarchy of civil aviators.

\subsection{Forecast demand for civil aviators}

\subsubsection{Analysis of demand for civil aviators}

This work compiled a flight schedule for all Taiwanese airlines as well as a statistical table of Taiwanese airlines of domestic flight by line of aviation in the Taiwan-Fuchien Area, and the number of airlines in Taiwan from 2000-2005, as listed in Table 1 [20]. Table 4 lists the 2000-2005 Statistics for passenger load factor of domestic flight by line of aviation in the Taiwan-Fuchien Area. Civil Aviation Law states that no pilot can fly while serving as a member of a flight crew more than 1,000 hours during any 12 -calendar-month period. Thus dividing Table 4 by 1000 hours yields the table of demand for aviators to pilot domestic flights during 2000-2005 (see Table 5). This information can then be used to create a table of Flight Times for International Flights by carrier in the TaiwanFuchien area during 2000-2005 (see Table 6). The total time is time from the moment an aeroplane first moves under its own power for the purpose of taking off until the moment it finally comes to rest at the end of the flight. This work defines flight time as being synonymous with the term "block to block" time or "chock to chock" time in general usage, namely the time from an aeroplane first moving for the purpose of taking off until it finally stops at the end of the flight. The total time counts from the moment an aircraft takes off until it touches down at the end of the flight. Total time is used for calculations and record keeping regarding the service time of the aircraft, engine, propeller, installations and equipment, unless the maintenance manual requires otherwise.

Simultaneously, based on the Civil Aviation Law, the pilot-in-command is responsible for aircraft operation and safety during flight. The flight crew must accord with the flight manual requirements for the specific type of aircraft, including a pilot-in-command, co-pilot and flight engineer if required. Civil aviation regulations restrict pilots in Taiwan from flying more than eight hours of domestic flights during any consecutive 24 -hour period. Furthermore, pilots should be permitted a rest period of no less than ten consecutive hours at the end of every eight scheduled hours of flight time. Meanwhile, on international flights, pilots may not fly more than ten hours during any consecutive 24 -hour period. The same rules apply to supporting flight crew members, including the pilot-in-command, cruise pilot and co-pilot; or a pilot-in-command, cruise pilot, co-pilot and two flight engineers or a pilot-in-command, captain, co-pilot and two flight engineers. Table 7 lists demand for civil aviators to fly international flights during 2000-2005, while

Table 4. 2000-2005 passenger load factor of domestic flight by line of aviation in the Taiwan-Fuchien area

\begin{tabular}{|l|c|c|c|c|c|c|}
\hline \multicolumn{1}{|c|}{ Year } & 2000 & 2001 & 2002 & 2003 & 2004 & 2005 \\
\hline Flights of domestic line & 222,024 & 202,923 & 191,978 & 168,440 & 161,863 & 146,114 \\
\hline The source of information: [20].
\end{tabular}

Table 5. 2000-2005 demand for civil aviators to crew domestic flights

\begin{tabular}{|l|c|c|c|c|c|c|}
\hline \multicolumn{1}{|c|}{ Year } & 2000 & 2001 & 2002 & 2003 & 2004 & 2005 \\
\hline Flights of domestic line & 222,024 & 202,923 & 191,978 & 168,440 & 161,863 & 146,114 \\
\hline Captain (per person) & 222 & 203 & 192 & 168 & 162 & 146 \\
\hline Co-pilot (per person) & 222 & 203 & 192 & 168 & 162 & 146 \\
\hline Total (per person) & 444 & 406 & 384 & 336 & 324 & 292 \\
\hline The source of information: [20].
\end{tabular}

Table 6. 2000-2005 flight times of international flights by line of aviation in the Taiwan-Fuchien area

\begin{tabular}{|l|c|c|c|c|c|c|}
\hline \multicolumn{1}{|c|}{ Year } & 2000 & 2001 & 2002 & 2003 & 2004 & 2005 \\
\hline $\begin{array}{l}\text { Flight Time under 10 hours of } \\
\text { international lines }\end{array}$ & 330162.15 & 355626.18 & 369218.72 & 348377.47 & 411636.77 & 434753.77 \\
\hline $\begin{array}{l}\text { Flight Time over 10 hours of international } \\
\text { lines }\end{array}$ & 150052.00 & 139627.50 & 144953.50 & 164158.20 & 174074.05 & 194956.55 \\
\hline The source of information: [20].
\end{tabular}

Table 7. 2000-2005 demand for civil aviators to crew international flights (unit: per person)

\begin{tabular}{|l|l|l|l|l|l|l|l|}
\hline \multicolumn{2}{|c|}{ Year } & 2000 & 2001 & 2002 & 2003 & 2004 & 2005 \\
\hline \multirow{2}{*}{ Flight Time under 10 hours } & Captain & 330 & 356 & 369 & 348 & 412 & 435 \\
\cline { 2 - 8 } & Co-pilot & 330 & 356 & 369 & 348 & 412 & 435 \\
\hline \multirow{2}{*}{ Flight Time over 10 hours } & Captain & 300 & 279 & 290 & 328 & 348 & 390 \\
\cline { 2 - 9 } & Co-pilot & 150 & 140 & 145 & 164 & 174 & 195 \\
\hline \multirow{2}{*}{ Total } & Captain & 630 & 635 & 659 & 676 & 760 & 825 \\
\cline { 2 - 8 } & Co-pilot & 480 & 496 & 514 & 512 & 586 & 630 \\
\hline
\end{tabular}


Table 8. 2000-2005 demand for civil aviators to crew Taiwanese airlines (unit: per person)

\begin{tabular}{|l|c|c|c|c|c|c|c|}
\hline \multicolumn{2}{|c|}{ Year } & 2000 & 2001 & 2002 & 2003 & 2004 & 2005 \\
\hline \multirow{2}{*}{ Flights of domestic line } & Captain & 222 & 203 & 192 & 168 & 162 & 146 \\
\cline { 2 - 9 } & Co-pilot & 222 & 203 & 192 & 168 & 162 & 146 \\
\hline \multirow{2}{*}{ Flights of international line } & Captain & 630 & 635 & 659 & 676 & 760 & 825 \\
\cline { 2 - 9 } & Co-pilot & 480 & 496 & 514 & 512 & 586 & 630 \\
\hline \multirow{2}{*}{ Total } & Captain & 852 & 838 & 851 & 844 & 922 & 971 \\
\cline { 2 - 8 } & Co-pilot & 702 & 699 & 706 & 680 & 748 & 776 \\
\hline
\end{tabular}

Table 8 lists demand for civil aviators to crew Taiwanese airlines during 2000-2005.

\subsubsection{Grey forecast of demand for civil aviators}

This forecast is based on demand for airline civil aviators to pilot aircraft in Taiwan. Consequently, the forecast annual number of Taiwanese airline pilots provides a proxy for annual demand for civil aviators. Based on the GM $(1,1)$ Grey model and the data listed in Table 8, this work calculates the number of captains for each year from 2000-2005. An explanation is given below: Eqn. (1) and Table 1 list primitive sequence $x^{(0)}$, that is

$$
x^{(0)}=(852,838,851,844,922,971) .
$$
of $x^{(1)}$

Moreover, Eqn. (2) yields a one order AGO sequence

$$
x^{(1)}=(852,1690,2541,3385,4307,5278) .
$$

Additionally, matrix $\mathrm{B}$ and constant vector $y_{n}$ are obtained as follows:

$$
B=\left[\begin{array}{ll}
-1271 & 1 \\
-2115.5 & 1 \\
-2963 & 1 \\
-3846 & 1 \\
-4792.5 & 1
\end{array}\right]
$$

and

$$
y_{n}=\left[\begin{array}{l}
838 \\
851 \\
844 \\
922 \\
971
\end{array}\right] .
$$

Equation (4) calculates $\hat{a}$ as

$$
\hat{a}=\left[\begin{array}{l}
a \\
b
\end{array}\right]=\left[\begin{array}{c}
-0.03873 \\
769.0959
\end{array}\right] .
$$

The forecasting model is obtained by substituting $a$ and $b$ into Eqn. (7)

$$
\hat{x}^{(0)}(k)=20708.68 e^{0.03873(k-1)}\left(1-e^{-0.03873}\right) .
$$

The forecast values of the total numbers of civil aviators for each year from 2000-2005 (702, 682, 702, 721, 741 and 762 , respectively), are calculated by substituting $k=2,3, \ldots, 6$ into Eqn. (10) and the reduction sequence is:

$$
\hat{x}^{(0)}=(702,682,702,721,741,762) .
$$

Table 2 reveals that the forecast value, actual value, and residual error can be calculated by substituting $x^{(0)}(k)$ and $\hat{x}^{(0)}(k), k=2,3, \ldots, 6$ into Eqn. (9) separately. Table 9 reveals that the average residual error is $1.8483361 \%$, while the average accuracy is $98.15166 \%$; moreover, the maximal residual error is $4.70 \%$ and the maximum accuracy is $99.90 \%$. The above statistics confirm the accuracy of the forecasting model.

Given $k=6,7,8,9,10$, from Eqn. (11), annual forecasts for the number of civil aviators for each year during the period 2006-2010 are 992, 1032, 1073, 1115, and 1159 , respectively. Table 10 lists the outcome.

Table 10 lists the number of scheduled flights operated by Taiwanese countrymen and the number of civil aviators at every level of the hierarchy. Numbers have increased owing to economic growth and consequent increased numbers of flights.

Table 9. Forecast value, real value and residual error for captain demand

\begin{tabular}{|l|c|c|c|c|c|}
\hline \multicolumn{1}{|c|}{ Year } & 2001 & 2002 & 2003 & 2004 & 2005 \\
\hline$k$ value & 2 & 3 & 4 & 5 & 6 \\
\hline $\begin{array}{l}\text { Actual quantity of } \\
\text { captain } x^{(0)}(k)\end{array}$ & 838 & 851 & 844 & 922 & 971 \\
\hline $\begin{array}{l}\text { Forecast quantity of } \\
\text { captain } \hat{x}^{(0)}(k)\end{array}$ & 818 & 850 & 884 & 919 & 955 \\
\hline Residual error $(\%) e(k)$ & 2.41 & 0.10 & 4.70 & 0.37 & 1.66 \\
\hline
\end{tabular}

Table 10. Forecast total demand for civil aviators for each year during the period 2006-2010 (unit: per person)

\begin{tabular}{|l|c|c|c|c|c|}
\hline \multicolumn{1}{|c|}{ Year } & 2006 & 2007 & 2008 & 2009 & 2010 \\
\hline Captain & 993 & 1,032 & 1,073 & 1,115 & 1,159 \\
\hline Co-pilot & 784 & 806 & 828 & 851 & 875 \\
\hline Total & 1,777 & 1,838 & 1,901 & 1,966 & 2,034 \\
\hline
\end{tabular}

\section{Conclusions}

This work devised the GM $(1,1)$ model of Grey Theory for forecasting total annual supply at each level in the hierarchy of civil aviators (Table 3 ) based on numbers of airline transport pilot licenses in Taiwan area from 2000-2005. The GM $(1,1)$ model of Grey Theory was also applied to forecast total annual demand for civil aviators (Table 10). While examining issues of manpower supply and demand for civil aviators in Taiwan, this 
Table 11. Supply and demand for Taiwanese civil aviators for 2000-2010 (unit: per person)

\begin{tabular}{|c|c|c|c|c|c|c|c|c|c|c|c|c|}
\hline \multicolumn{2}{|c|}{ Year } & 2000 & 2001 & 2002 & 2003 & 2004 & 2005 & $2006 \dagger$ & $2007 \dagger$ & $2008 \dagger$ & $2009 \dagger$ & $2010 \dagger$ \\
\hline \multirow{3}{*}{$\begin{array}{l}\text { Supply of } \\
\text { Taiwanese civil } \\
\text { aviators }\end{array}$} & Captain & 621 & 658 & 677 & 695 & 712 & 724 & 745 & 763 & 781 & 800 & 820 \\
\hline & Co-pilot & 824 & 825 & 781 & 760 & 769 & 796 & 765 & 758 & 751 & 744 & 738 \\
\hline & \begin{tabular}{|l|} 
Total \\
\end{tabular} & 1,445 & 1,483 & 1,458 & 1,455 & 1,481 & 1,520 & 1,510 & 1,521 & 1,532 & 1,544 & 1,558 \\
\hline \multirow{3}{*}{$\begin{array}{l}\text { Demand for } \\
\text { Taiwanese civil } \\
\text { aviators }\end{array}$} & Captain & 852 & 838 & 851 & 844 & 922 & 971 & 993 & 1,032 & 1,073 & 1,115 & 1,159 \\
\hline & Co-pilot & 702 & 699 & 706 & 680 & 748 & 776 & 784 & 806 & 828 & 851 & 875 \\
\hline & \begin{tabular}{|l|} 
Total \\
\end{tabular} & 1,554 & 1,537 & 1,557 & 1,524 & 1,670 & 1,747 & 1,777 & 1,838 & 1,901 & 1,966 & 2,034 \\
\hline
\end{tabular}

Table 12. Imbalance between supply and demand for air aviators

\begin{tabular}{|l|c|c|c|c|c|c|c|c|c|c|c|}
\hline \multicolumn{1}{|c|}{ Year } & 2000 & 2001 & 2002 & 2003 & 2004 & 2005 & $2006 \dagger$ & $2007 \dagger$ & $2008 \dagger$ & $2009 \dagger$ & $2010 \dagger$ \\
\hline Captain (\%) & -27.11 & -21.48 & -20.45 & -17.65 & -22.78 & -25.44 & -24.97 & -26.07 & -27.21 & -28.25 & -29.25 \\
\hline Co-pilot (\%) & +17.38 & +18.03 & +10.62 & +11.76 & +2.81 & +2.58 & -2.42 & -5.96 & -9.30 & -12.57 & -15.66 \\
\hline Total & -7.01 & -3.51 & -6.36 & -4.53 & -11.32 & -12.99 & -15.03 & -17.25 & -19.41 & -21.46 & -23.40 \\
\hline $\begin{array}{l}\text { †Projected values; } \\
\text { +indicates ratio of supply over demand; } \\
- \text { indicates ratio of supply surplus demand }\end{array}$
\end{tabular}

work also identified some important outcomes, which can provide a valuable reference for the relevant governmental authorities in devising labor policy for civil aviators in Taiwan. The information listed in Tables 1, 3 and 10 included the actual and forecast values for supply and demand for civil aviators from 2000-2005, as listed in Table 11. To further discuss the manpower problem related to demand and supply of civil aviators in Taiwan, the data in Table 11 were adjusted to obtain the annual imbalance ratio of supply and demand for air aviators, as listed in Table 12.

The following conclusions summarize the information listed in Tables 11 and 12:

(1) The forecast number of civil aviators in Taiwan for 2006-2010 indicates not only a situation of demand exceeding supply, but also an imbalance that is steadily worsening. The annual imbalance between supply and demand for civil aviators for the five years in question were $-15.03 \%,-17.25 \%,-19.41 \%,-21.46 \%$ and $-23.40 \%$ annually.

(2) The imbalances between supply and demand for civil aviation captains in Taiwan for each year during the period from 2006 to 2010 were $-24.97 \%,-26.07 \%$, $-27.21 \%,-28.25 \%$ and $-29.25 \%$, respectively. Meanwhile, the imbalances between demand and supply for co-pilots involved in civil aviation were $-2.42 \%,-5.96 \%$, $-9.30 \%,-12.57 \%$ and $-15.66 \%$, respectively. Restated, the imbalance in supply and demand for civil aviators in Taiwan was worst for captains, while for co-pilots the imbalance was significantly less.

\section{Recommendations}

To effectively adjust the imbalance of supply and demand for civil aviators, increased attention should be paid to the supply of captains. Graduates from the single Flight Technology and Flight University in Taiwan generally do not wish to work as pilots. This phenomenon negatively impacts the supply of civil aviation co-pilots and indirectly influences the supply of civil aviation captains. This work makes the following recommendations to address the problem of demand for civil aviators exceeding supply:

1. Cherng and Ho [21] demonstrated that $80.4 \%$ of pilots in Taiwan are Taiwanese, with the remaining $19.6 \%$ coming from elsewhere. Additionally, the breakdown of pilots in Taiwan by training is believed to be as follows: ex-military pilots (41.0\%), CPL pilots and sponsored pilot training scheme (53.1\%), and others (5.9\%). The government should substitute military service by providing air internships for students of aerospace engineering, avionics, aviation mechanical engineering and aviation management. Alternatively, the government could subsidize civil aviation pilot tuition fees, just as it subsidizes the education of teachers and military personnel.

2. Demand is expected to continue increasing in future. Taiwanese airlines are also looking to recruit foreign captains. Suen and Liang [7] analyzed native pilot selection for ratios of civilian airliners, and found that education requirements, flight experience and flight hours and foreign language are effective characteristics. Airlines value the flight experience and flight hours of ex-military pilots but neglect related educational requirements. Additionally, in pilot recruitment airlines stress the foreign language skills of ex-military pilots and CPL pilots. Government and non-governmental organizations thus should establish training institutes to provide official education to aviators, thus countering the current weakness of official education. Moreover, the airlines can cooperate with the Ministry of Foreign Affairs and encourage students to study abroad with a particular focus on engineering science.

3. Airline companies should encourage aviators to exploit the opportunity to transfer inland and possibilities for promotion, using a combination of vacation and end-of-year bonuses, to condense their cen- 
tripetal force. Shenzhen Government Online Local News [21] commented that Taiwanese pilots find it easier to communicate with their Mainland Chinese colleagues, because the Taiwanese and Mainland Chinese share a common language and culture. Furthermore, the Taiwanese aviation industry provides significantly fewer opportunities to pilots than that on the mainland.

4. During aircraft flight decks, the auto-pilot, speedcontrol and systems-monitoring functions of flight management systems (FMSs) have improved safety and freed pilots from much of the routine mechanical work involved in flying [22].

\section{References}

1. BUTKEVIČIUS, J.; JARAŠŪNIENĖ, A. World tendences of civil aviation development and the enlargement of the Lithuanian civil aviation. Transport, 2006, Vol. 21, No. 2, p. 141-147.

2. IATA. IATA passenger and freight forecast 2005-2009. Passenger and Freight Forecast Publications [accessed 27.6.2006]. Available from Internet: <www.iata. org/NR/rdonlyres/CC8F53FF-D587-4C7A-8CDA1E9F5835531E/0/PressPackPassengerandFreightForecasts20052009.pdf>.

3. XINHUANET. Airlines ready for historic non-stop flights to Taiwan. Xinhua English. January, 2005 [accessed 27.6.2006]. Available from Internet: <english.sina.com/taiwan_hk/p/1/2005/0126/19353.html>.

4. LIN, C.-C.; CHEN, Y.-C. The integration of Taiwanese and Chinese air networks for direct air cargo services. Transportation Research Part A, 2003, 37, p. 629-647.

5. GIO. Civil Aviation. Taiwan Yearbook [accessed 27.6.2006]. Available from Internet: <english.www.gov.tw/Yearbook/ index.jsp? categid $=163 \&$ recordid $=83368>$.

6. TAIWAN QUCIK TAKE. China Airlines recruiting. The Taipei Times. March, 2006 [accessed 27.6.2006]. Available from Internet: <www.taipeitimes.com/News/taiwan/archives/2006/03/06/2003296092>.

7. SUEN, H. J.; LIANG, G. S. Analysis of native pilot selection for civilian airliners. Civil Aviation Journal, 2004, 6 (4), p. 13-32.

8. LUCIC, P.; TEODOROVIC, D. Simulated annealing for the multi-objective aircrew rostering problem. Transportation Research Part A, 1999, 33, p. 19-45.

9. YAN, S.; YANG, T.-H.; CHEN, H.-H. Airline short-term maintenance of manpower supply planning. Transportation Research Part A, 2004, 38, p. 615-642.

10. MAZÜRA, M. Predictions of major trends of transportation development. Transport, 2002, Vol. XVII, No. 2, p. 57-59.

11. MAZÜRA, M.; FADINA, O. The reliatibility of forecasts in transportation. Transport, 2002, Vol. XVII, No. 6, p. 219-222.

12. BUTKEVIČIUS, J.; MAZÜRA, M.; IVANKOVAS, V.; MAZŪRA, S. Analysis and forecast of the dynamics of passenger transportation by public land transport. Transport, 2004, Vol. XIX, No. 1, p. 3-8.

13. KUGELEVIČIUS, J. A.; KUPRYS, A.; KUGELEVIČIUS, J. Forecasts of petroleum demand. Transport, 2007, Vol. XXII, No. 1, p. 9-13.

14. WEN, K. L. Grey systems: modeling and prediction. Yang's Scientific Research Institute, AZ. USA, 2004.
15. HILLER, S. F.; LIEBERMAN, J. G. Introduction to operations research. McGraw-Hill Inc, New York, 1995.

16. DENG, J. L. Control problems of grey system. System and Control Letters, 1982, 5, p. 288-294.

17. YI, D. Grey Model and forecast of talented persons. System Engineering, 1987, 11, p. 36-43.

18. LIN, C. T.; HSU, P. F. Forecast advertising revenue for the five largest media internet in Taiwan using grey theory, and a comparison trends between Taiwan and Japan. Journal of International Marketing \& Marketing Research, 2002, 27(2), p. $45-55$.

19. LIN, C.T.; WANG, S.M.; CHIANG, C.T. Manpower supply and demand of ocean deck officers in Taiwan. Maritime Policy \& Management, 2001, 28(1), p. 91-102.

20. CAA (Civil Aeronautics Administration Ministry of Transportation and Communications), 2006. Civil Air Transportation Statistics. Civil Aeronautics Administration Ministry of Transportation and Communications [accessed 14.6.2006]. Available from Internet: <www.caa.gov.tw $>$.

21. SHENZHEN GOVERNMENT ONLINE LOCAL NEWS. Taiwan pilots seek SZ jobs. Shenzhen Government Online/Local News. July, 2006 [accessed 11.7.2006]. Available from Internet: <english.sz.gov.cn/ln/200602/t37875. htm>.

22. BURROWS, G.; BROWN, C. A.; THOM, T. W.; KING, J. M. C.; FREARSON, J. Real-time cost management of aircraft operations. Management Accounting Research, 2001, 12, p. 281-298. 